\title{
Model Layanan BK AUD Dengan Teknik Biblioterapi Untuk Meningkatkan Perilaku Empati
}

\author{
Chitra Charisma Islami ${ }^{1}$, Mira Mayasarokh ${ }^{2}$ \\ 1,2Pendididan Guru Pendidikan Anak Usia Dini, STKIP Muhmmdiyah Kuningan \\ Email: chitra@upmk.ac.id ${ }^{1}$,miramayasarokh@upmk.ac.id²
}

\begin{abstract}
Abstrak:
Layanan bimbingan konseling perlu di terapkan di semua jenjang pendidikan dikarenakan proses pengalaman belajar dan pembelajaran di tingkat pendidikan usia dini dan sekolah dasar akan berpengaruh terhadap perilaku di masa depannya di tingkat sekolah menengah pertama, sekolah menengah atas maupun tingkat perguruan tinggi. Untuk itu berdasarkan hasil dari pra-penelitian yang diperoleh dan didukung oleh pendapat para ahli perlu adanya model layanan BK AUD dengan teknik biblioterapi untuk meningkatkan perilaku empati. Jenis penelitian ini adalah penelitian dan pengembangan (research and development) yang didasarkan pada prinsip-prinsip dan langkah-langkah dari Borg \& Gall. Dari penelitian ini dihasilkan: Tingkat perilaku empati siswa di Kober Rabbani secara global sebelum diberi perlakuan berada pada kategori sedang, setelah diberikan perlakuan berada pada kategori tinggi. Dihasilkan model layanan BK AUD dengan teknik biblioterapi untuk meningkatkan perilaku empati aud yang terdiri dari 7 komponen yaitu Rasional, Visi dan misi, Tujuan, Isi Layanan BK siswa PAUD dengan teknik biblioterapi, Dukungan Sistem, Prosedur Layanan BK siswa PAUD dengan teknik biblioterapi, Evaluasi dan Tindak Lanjut. Model Layanan BK AUD dengan teknik biblioterapi efektif dalam meningkatkan perilaku empati siswa Kober Rabbani.
\end{abstract}

Kata Kunci: BK AUD, Teknik Biblioterapi, Empati.

\begin{abstract}
:
Counseling guidance services need to be applied at all levels of education because the process of learning and learning experiences at the early childhood and elementary school levels will affect future behavior at the junior high school, high school and college levels. For this reason, based on the results of pre-research obtained and supported by expert opinion, it is necessary to have a BK AUD service model with bibliotherapy techniques to improve empathy behavior. This type of research is research and development which is based on the principles and steps of Borg \& Gall. This research resulted: The level of empathy behavior of students in Kober Rabbani globally before being treated was in the medium category, after being given treatment it was in the high category. The resulting BK AUD service model with bibliotherapy techniques to improve empathy aud behavior which consists of 7 components, namely Rational, Vision and Mission, Objectives, BK service content for PAUD students with bibliotherapy techniques, System Support, BK service procedures for PAUD students with bibliotherapy techniques, evaluation and Follow-up. The BK AUD Service Model with bibliotherapy techniques is effective in increasing the empathy behavior of Kober Rabbani students.
\end{abstract}

Keywords: BK AUD, Bibliotherapy Technique, Empathy. 


\section{PENDAHULUAN}

Norton, Michael I (Norton \& Michael, 2013) memaparkan dalam penelitiannya yang berjudul Prosocial Spending and Well-Being: Cross-Cultural Evidence for a Psychological Universal. Penelitian Norton dan Michael ini memberikan dukungan perkembangan ilmu psikologi bahwa manusia di dunia ini merasa memiliki manfaat emosional dengan menampilkan perilaku empati. Berdasarkan hasil penelitian menggunakan analisis product moment dari Spearman's dengan menggunakan bantuan program SPSS 15.0 for windows diperoleh hasil koefisien korelasi rxy $=0,462$ dengan sig. $=0,000 ;(p<0,01)$. Hasil ini menunjukkan ada hubungan positif yang sangat signifikan antara variabel empati dengan perilaku prososial. Artinya semakin tinggi empati maka semakin tinggi perilaku prososial. Sebaliknya, semakin rendah empati yang dimiliki oleh siswa maka semakin rendah pula perilaku prososial (Oktaviani, 2016). Perilaku prososial juga berkaitan sekali dengan cara berpikir, menggunakan perasaan, empati dan berperilaku. Oleh karena itu, pada bimbingan dan konseling dengan teknik outbound yang sangat cocok digunakan dalam permasalahan tersebut. Teknik outbound tujuan umum yaitu membantu individu suatu bentuk dari pembelajaran segala ilmu terapan yang disulasikan dan dilakukan di alam terbuka atau tertutup dengan bentuk permainan yang efektif, yang menggabungkan antara intelegensia, fisik dan mental. Secara konseling tersebut memusatkan perhatian pada upaya membantu individu untuk belajar memperoleh keterampilan yang memudahkannya untuk membentuk pikiran-pikiran yang lebih rasional, mengarahkan pada tolong menolong, kebahagiaan yang lebih besar dan mendorong kesanggupan untuk dapat lebih menikmati hidupnya (Sabela \& Komariah, 2020).

Sementara itu, Sari (Sari, 2013) dalam penelitian yang menggunakan metode penelitian dan pengembangan (Research and Development) memaparkan bahwa berdasarkan hasil uji lapangan diketahui bahwa model bimbingan kelompok dengan teknik sosiodrama terbukti efektif dalam meningkatkan sikap empati siswa. Hasil yang signifikan output $=0.00$ $<5 \%$, yang berarti ada perbedaan yang signifikan antara sikap empati siswa sebelum diberikan perlakuan (pre-test) dan setelah pengobatan yang diberikan (post-test). Salah satu upaya yang perlu dilakukan untuk membantu siswa meningkatkan sikap empati dengan mengoptimalkan bimbingan kelompok. Seperti halnya kasus-kasus yang sering terjadi di lingkungan sekitar diantaranya kasus tawuran di tingkat SMP, SMA maupun perguruan tinggi. Selain itu juga kasus lain yang dapat di katagorikan sebagai krisis sosial adalah kasus para pejabat yang tesangkut masalah korupsi. Krisis sosial tersebut dapat dianalisis salah satu penyebabnya adalah kurangnya atau malah tidak adanya penanaman nilai-nilai empati di jenjang pendidikan dasar (Islami \& Gustiana, 2020).

Sementara itu penelitian yang lain menjelaskan bahwa storytelling memberikan pengaruh pada perilaku empati anak, khususnya pada aspek fantasi. Hal ini terlihat dari hasil analisis dengan menggunakan independent sample t-test yang menunjukkan nilai signifikansi $(0,044<\alpha=0,05)$. Nilai ini menunjukkan bahwa ada peningkatan pada aspek fantasi pada kelompok eksperimen setelah diberi perlakuan storytelling. Analisis deskriptif kuantitatif yang telah dilakukan pada kelompok ekperimen dengan meggunakan grafik visual juga menunjukkan adanya peningkatan dalam aspek fantasy, empathic concern, perspective taking dan penurunan pada aspek personal distress (Ayuni, Siswanti, \& Rusmawati, 2013). 
Salah satu usaha yang bisa diupayakan adalah melalui jalur pendidikan. Tujuan pendidikan seutuhnya adalah membantu siswa mencapai perkembangan secara optimal. Jadi bisa dimaknai bukan hanya aspek kognitif atau akademik saja yang perlu ditingkatkan dalam pendidikan. Akan tetapi semua aspek termasuk di dalamnya aspek non kognitif yang meliputi aspek afektif dan psikomotornya. Disisi lain mengapa perlu di terapkannya layanan bimbingan konseling di semua jenjang pendidikan dikarenakan proses pengalaman belajar dan pembelajaran di tingkat pendidikan usia dini dan sekolah dasar akan berpengaruh terhadap perilaku di masa depannya di tingkat sekolah menengah pertama, sekolah menengah atas maupun tingkat perguruan tinggi. Jadi proses layananan bimbingan konseling merupakan suatu proses berkelanjutan yang di perlukan agar kondisi siswa dapat tetap di kontrol dengan baik.

Kondisi siswa yang dituntut untuk lebih mementingkan aspek akademis daripada aspek lainnya. Kondisi tersebut dapat dibuktikan dari kategori yang disyaratkan sebagai kualifikasi seseorang bisa masuk sekolah dasar tertentu menghendaki harus sudah pandai CaLisTung untuk masuk SD dan jika di runtut beberapa pendidikan anak usia dini menerapkan pembelajaran tambahan CaLisTung karena guru PAUD di tuntut oleh orangtua siswa untuk memberikan pelajaran tambahan tersebut dengan alasan agar anaknya dapat masuk SD terbaik, padahal sudah jelas bahwa pendidikan anak usia dini dilarang untuk menerapkan pembelajaran CaLisTung karena konsep belajar anak usia dini adalah bermain sambil belajar. Hal ini yang memunculkan teori tentang cara mengukur kecerdasan otak yang dikenal dengan IQ (Islami \& Muhammad, Development of Guidance ang Counseling's Model Services with Bibliotherapy Techniques to Improve Prosocial Behavior for Student of Primary School, 2019).

Seperti hasil penelitian yang dihimpun oleh Rosen dkk (2010:19) bahwa semua studi yang melibatkan perilaku empati sebagai hasil atau prediktor menunjukkan pandangan positif terhadap kegiatan diinginkan akademik dan hasil-hasil sosial seperti pemahaman komunikasi, menyelesaikan sekolah, persahabatan, penerimaan orang lain, dan status pekerjaan. Disinilah arti penting dikembangkannya perilaku empati siswa. Pengembangan perilaku empati sangat dimungkinkan dilaksanakan di lingkungan sekolah. Karena sebagian waktunya siswa menghabiskan di sekolah. Siswa bertemu dengan siswa lain dalam kondisi demikian mereka memiliki kesempatan untuk menjalin hubungan dan interaksi sosial. Bagaimana mereka bekerjasama, berempati, saling menolong, berbagi serta menghormati satu sama lain. Keberhasilan proses pendidikan di sekolah akan dapat dicapai apabila semua komponen pendidikan akan saling mendukung dan menunjang. Siswa yang aktif, pendidik yang profesional, suasana belajar yang kondusif, sarana dan prasarana yang menunjang, pemanfaatan teknologi secara tepat, serta manajemen yang bermutu merupakan berbagai hal yang harus dipertimbangkan dalam proses pendidikan.

Sementara itu kondisi guru BK yang kompeten belum di temukan di PAUD, untuk itu perlu adanya alternatif agar proses layanan BK di Sekolah dapat berjalan lancar serta bertanggungjawab. Peneliti mengamati guru wali kelas yang terlatih dengan kompetensi BK menjadi alternatif yang dapat di pilih agar proses layanan BK di PAUD dalam hal ini Kober dapat berjalan dengan lancar. Menurut Shechtman (2009) (dalam Eva Imania Eliasa Bibliotherapy As A Method of Meaningful Treatment. ISSN 114 434-438) menekankan bahwa "Bibliotherapyentails the use of literature for therapeutic purposes and it includes listening to storiesand poems, watching films, and looking at pictures. It is a playful, 
engaging, and fun process." Shechtman mengkombinasikan kegiatan mendengarkan cerita, membaca puisi,menonton film dan gambar dilakukan didalam rangkaian bibliotherapy, sehingga aktivitas berjalan menarik dan menyenangkan (Solikin, 2015). Untuk itu berdasarkan hasil dari pra-penelitian yang diperoleh dan didukung oleh pendapat para ahli perlu adanya model layanan BK AUD dengan teknik bibilioterapi untuk meningkatkan perilaku empati. Permasalahan yang diteliti yaitu bagaimana mengembangkan model layanan BK AUD yang valid dan tepat serta dapat digunakan oleh guru yang berkompeten.

\section{METODE PENELITIAN}

Pada penelitian ini, peneliti menggunakan metode dan desain penelitian dan pengembangan (research and development) yang didasarkan pada prinsip-prinsip dan langkah-langkah dari Borg \& Gall. Borg \& Gall (Borg \& Gall, 1983) langkah-langkah yang harus ditempuh dalam penelitian dan pengembangan, antara lain: (a) studi pendahuluan, (b) perencanaan, (c) pengembangan model hipotetik, (d) penelaahan model hipotetik, (e) revisi, (f) uji coba terbatas, (g) revisi hasil uji coba, (h) uji coba lebih luas, (i) revisi model akhir, dan (j) diseminasi dan sosialisasi. Namun, dalam penelitian ini kesepuluh langkah tersebut akan dimodifikasi menjadi enam langkah yang disesuaikan dengan kebutuhan penelitian.

Instrumen yang digunakan dalam penelitian ini dibagi menjadi dua bagian yaitu instrumen yang digunakan pada tahap studi pendahuluan dan instrumen yang digunakan pada tahap pengembangan. Dalam penelitian uji analisis yang digunakan adalah dengan menggunakan analisis data kualitatif dan pendekatan analisis data kuantitatif. Analisis data kualitatif digunakan untuk menganalisis data hasil dari observasi yang telah dilaksanakan terkait dengan bimbingan konseling di PAUD. Dari hasil analisis data kualitatif akan bisa digambarkan secara terperinci dan mendalam fenomena sosial tertentu. Analisis data kuantitatif adalah data-data yang terkumpul untuk menguji hipotesis dalam penelitian ini dianalisa dengan menggunakan teknik statistik non parametris, yaitu menggunakan Tes rangking bertanda (Wilcoxon Test). Penggunaan Wilcoxon Test untuk menguji siginfikansi hipotesis komparatif dua sampel yang berkorelasi bila datanya berbentuk ordinal atau berjenjang. Tes wilcoxon dicari dengan membandingkan skor sebelum (pretes) dan sesudah (postest) treatment atau perlakuan. Selanjutnya selisih skor pretes dan postest diberi rangking (jenjang). Penentuan rangking atau jenjang dimulai dari beda yang terkecil sampai yang terbesar.

\section{HASIL DAN PEMBAHASAN}

Dari penelitian yang dilakukan oleh peneliti, peneliti mendapatkan hasil yang dilakukan sebelum pelaksaan layanan BK AUD dengan teknik biblioterapi untuk meningkatkan perilaku empati. Lebih detailnya dijelaskan di tabel 1:

Tabel 1. Perbandingan Skor Evaluasi Awal dan Evaluasi Akhir

\begin{tabular}{clccccl}
\hline No & Siswa & $\begin{array}{c}\text { Evaluasi } \\
\text { Awal }\end{array}$ & $\begin{array}{c}\text { Evaluasi } \\
\text { Akhir }\end{array}$ & $\begin{array}{c}\text { Perubahan } \\
\text { Skor }\end{array}$ & Ket. & Perubahan Kategori \\
\hline 1 & AA & 135 & 166 & 31 & 16,85 & sangat rendah menjadi rendah \\
2 & ANK & 141 & 169 & 28 & 15,22 & sedang menjadi tinggi \\
3 & GAA & 130 & 164 & 34 & 18,48 & rendah menjadi sedang
\end{tabular}




\begin{tabular}{clccccl}
\hline No & Siswa & $\begin{array}{c}\text { Evaluasi } \\
\text { Awal }\end{array}$ & $\begin{array}{c}\text { Evaluasi } \\
\text { Akhir }\end{array}$ & $\begin{array}{c}\text { Perubahan } \\
\text { Skor }\end{array}$ & Ket. & Perubahan Kategori \\
\hline 4 & IAR & 145 & 175 & 30 & 16,30 & sedang menjadi tinggi \\
5 & MG & 136 & 161 & 25 & 13,59 & rendah menjadi sedang \\
6 & SNF & 137 & 166 & 29 & 15,76 & sedang menjadi tinggi \\
7 & AKPR & 133 & 161 & 28 & 15,22 & rendah menjadi tinggi \\
8 & SR & 142 & 176 & 34 & 18,48 & sedang menjadi tinggi \\
9 & ADM & 131 & 164 & 33 & 17,93 & sedang menjadi tinggi \\
10 & AMP & 125 & 158 & 33 & 17,93 & sangat rendah menjadi rendah \\
\hline Jumlah & 1355 & 1660 & 305 & & \\
\hline
\end{tabular}

Perilaku empati siswa pada seluruh indikator mengalami peningkatan sejumlah 305 poin setelah diberikan perlakuan. Artinya bahwa layanan bimbingan konseling anak usia dini dengan teknik biblioterapi efektif meningkatkan perilaku empati. Secara lebih detail digambarkan pada grafik dibawah ini.

Berdasarkan data di atas dapat dipahami bahwa dari 10 siswa setelah diberi perlakuan melalui model layanan bimbingan konseling AUD dengan teknik biblioterapi mengalami perubahan sebagai berikut: yang berawal dari kategori sangat rendah berubah menjadi kategori rendah berjumlah 2 orang siswa (20\%), yang berawal dari kategori rendah menjadi kategori sedang berjumlah 2 orang siswa (20\%), yang berawal dari kategori sedang menjadi kategori tinggi berjumlah 5 orang siswa (50\%), dan yang berawal dari kategori rendah menjadi kategori tinggi berjumlah 1 orang siswa (10\%).

Hasil perbandingan skor antara evaluasi awal dan evaluasi akhir di atas dikuatkan dengan hasil uji wilcoxon pada tabel 2

\section{Tabel 2 Hasil Perhitungan Wilcoxon}

\begin{tabular}{ccccc}
\hline & & $N$ & Mean Rank & Sum of Ranks \\
\hline Evaluasi & Negative & $0^{a}$ & .00 & .00 \\
Awal- & Ranks & $17^{b}$ & 9.00 & 153.00 \\
Evaluasi & Positive & $9^{c}$ & & \\
Akhir & Ranks & 26 & &
\end{tabular}

Ties

Total

\section{Test Statistic}

\begin{tabular}{ll}
\hline & $\begin{array}{l}\text { Evaluasi Akhir- } \\
\text { Evaluasi Awal }\end{array}$ \\
\hline$Z$ & $-3.625^{a}$ \\
Asymp.Sig. (2-tailed) & .001 \\
\hline
\end{tabular}


Berdasarkan hasil analisis data dengan Wilcoxon menunjukkan bahwa tujuan dari model layanan BK AUD dengan teknik biblioterapi untuk meningkatkan perilaku empati tercapai, yakni dengan adanya perubahan hasil evaluasi awal dan hasil evaluasi akhir pada perilaku empati yang dimiliki oleh siswa Kober Rabani Kuningan.

Kaidah yang digunakan adalah menguji hipotesis alternatif (Ha) yang berbunyi model layanan bimbingan konseling siswa sekolah dasar dengan teknik biblioterapi untuk meningkatan perilaku empati. Berdasarkan hasil pengujian wilcoxon, diperoleh perbedaan sebesar -3.625 pada nilai signifikansi hitung (sig.2taled) 0,001. Perbandingan nilai signifikansi hitung dengan pada taraf signifikansi 5\% $(0,05)$ adalah $0,001<0,05$ sehingga hipotesis nihil (Ho) ditolak sedangkan hipotesis alternatif (Ha) diterima. Sehingga terbukti efektif untuk meningkatkan perilaku empati siswa.

\section{Pembahasan}

Model layanan BK AUD dengan teknik biblioterapi yang dirumuskan dalam penelitian ini adalah layanan BK AUD dengan teknik biblioterapi untuk meningkatkan perilaku empati. Asumsinya bahwa persoalan perilaku empati perlu dikembangkan secara optimal dikarenakan perilaku empati memiliki kontribusi terhadap keberhasilan siswa dalam hidup sebenarnya di masyarakat.

Perilaku empati dipandang sebagai hal yang utama yang diperlukan dalam kehidupan manusia. Dampak positif yang dimiliki individu dengan perilaku empati diantaranya adalah bisa diterima lingkungan. Karena dengan adanya perilaku empati akan muncul atmosfer yang sehat dan kondusif dalam hubungan individu dengan individu lainnya, misalnya adalah terciptanya rasa saling menghormati, bekerjasama, berbagi, toleransi, empati, dan saling menghargai antar individu. Bisa dipastikan jika perilaku empati bisa ditanamkan dengan baik dan dimiliki oleh setiap individu, akan muncul lingkungan hidup yang aman, nyaman, damai, dan kondusif.

Menurut Albert dkk (Albert \& T, 2013) perilaku empati dapat didefinisikan sebagai perilaku sukarela yang dibuat dengan maksud untuk membawa manfaat bagi sesama atau masyarakat. empati dapat diwujudkan dengan membauat orang lain bahagia, meskipun kemurahan hati dapat diasumsikan berbagai bentuk, misalnya memberi sesuatu kepada orang lain yang sering melibatkan pengorbanan uang atau jasa (Liu \& Aaker, 2008 dalam Norton dkk (2013: 635-652, Vol. 104, No. 4).

Perilaku empati, atau "perilaku sukarela yang dimaksudkan untuk menguntungkan lain", terdiri dari tindakan yang menguntungkan orang lain atau masyarakat secara keseluruhan, misalnya membantu, berbagi, menyumbang, bekerja sama dan sukarela. Itu bisa juga disebut sebagai kategori perilaku yang mencakup salah satu tindakan yang memberikan manfaat kepada orang lain seperti mengikuti aturan-aturan dalam kegiatan, jujur, dan bekerja sama dengan orang lain dalam situasi sosial. Tindakan ini mungkin termotivasi oleh rasa empati dan kekhawatiran tentang kesejahteraan dan hak-hak orang lain, dan juga tindakan prihatin akan perilaku egois. (Eisenberg, Fabes dan Spinrad, 2006 dalam Afolabi, 2014:241 .Vol.10, No.2 ISSN: 1857 - 7881 (Print) e - ISSN 1857- 7431). Lebih dalam lagi Afolabi (2014:242) menjelaskan makna dari perilaku empati adalah adalah tindakan yang dilakukan atau direncanakan untuk membantu orang lain, dengan mengabaikan motif penolong. Dalam 
hal ini melibatkan bantuan yang tulus (altruisme) yang sepenuhnya didorong oleh kepentingan pribadi. Perilaku empati direncanakan dan dilakukan untuk membantu orang lain tanpa mengharapkan imbalan atau pamrih. Perilaku empati melibatkan perhatian dan bantuan terhadap orang lain, atau pengabdian (cinta, kesetiaan, layanan) yang diberikan kepada orang lain tanpa harapan untuk mendapatkan sesuatu sebagai balasannya (Afolabi \& Olukayode, 2014, hal. 242)

Baron (Baron, Robert, \& Byrne, 2005) mendefinisikan tingkah laku empati adalah suatu tindakan menolong yang menguntungkan orang lain tanpa harus menyediakan suatu keuntungan langsung kepada orang yang melakukan tindakan tersebut, dan mungkin bahkan melibatkan suatu resiko bagi orang yang menolong. Dayakisni (2009:176) menyimpulkan sikap empati adalah segala bentuk sikap yang memberikan konsekuensi positif bagi si penerima, baik dalam bentuk materi, fisik ataupun psikologis tetapi tidak memiliki keuntungan yang jelas bagi pemiliknya.

Anak-anak usia sekolah ini memiliki karakteristik yang berbeda dengan anak-anak yang usianya lebih muda. Ia senang bermain, senang bergerak, senang bekerja dalam kelompok, dan senang merasakan atau melakukan sesuatu secara langsung. Oleh sebab itu, guru hendaknya mengembangkan pembelajaran yang mengandung unsur permainan, mengusahakan siswa berpindah atau bergerak, bekerja atau belajar dalam kelompok serta memberikan kesempatan untuk terlibat langsung dalam pembelajaran. Teknik biblioterapi dalam layanan bimbingan konseling anak usia dini ini dapat digunakan sebagai peningkatan perilaku empati dengan menggunakan teknik layanan yang sesuai dengan usianya dan efektif dilaksanakan untuk meningkatkan perilaku empati.

\section{KESIMPULAN}

Berdasarkan hasil penelitian, maka dapat disimpulkan: Tingkat perilaku empati siswa Kober Rabbani secara global sebelum diberi perlakuan berada pada kategori sedang, setelah diberikan perlakuan berada pada kategori tinggi. Dihasilkan model layanan BK AUD dengan teknik biblioterapi untuk meningkatkan perilaku empati siswa yang terdiri dari 7 komponen yaitu Rasional, Visi dan misi, Tujuan, Isi Layanan BK siswa PAUD dengan teknik biblioterapi, Dukungan Sistem, Prosedur Layanan BK siswa PAUD dengan teknik biblioterapi, Evaluasi dan Tindak Lanjut. Model Layanan BK siswa PAUD dengan teknik biblioterapi efektif dalam meningkatkan perilaku empati siswa PAUD Kober Rabbani.

\section{Daftar Pustaka}

Afolabi, \& Olukayode, A. (2014). Psychosocial Predictors of Prosocial Behaviour Among a Sample of Negerian Undergraduates. European Scientific Journal January, 10(2), - .

Albert, A. P., \& T, T. (2013). A Study on Pro-Social Behaviour and Parental Behaviour of Higher Secondary Students. International Journal of Science and Research (IJSR), --

Ayuni, R. D., Siswanti, \& Rusmawati, D. (2013). Pengaruh Storytelling Terhadap Perilaku Empati Anak. Jurnal Psikologi Undip, 81-130.

Baron, Robert, A., \& Byrne, D. (2005). Psikologi Sosial. Jakarta: Erlangga.

Borg, W. R., \& Gall, M. D. (1983). Educational Research: An Introduction. New York and London: Longman. 
Islami, C. C., \& Gustiana, E. (2020). Layanan Bimbingan dan Konseling AUD Berbasis Tugas Perkembangan untuk Meningkatkan Perilaku Prososial. JAMBURA Early Childhood Education Journal, 70-78.

Islami, C. C., \& Muhammad, N. (2019). Development of Guidance ang Counseling's Model Services with Bibliotherapy Techniques to Improve Prosocial Behavior for Student of Primary School. The 1st International Conference on Computer, Science, Engineering and Technology. 1179, hal. 1-6. United Kingdom: IOP Publishing.

Norton, \& Michael, I. (2013). Prosocial Spending and Well-Being:Cross-Culture Evidence for a Psychological Universal. Journal of Personality and Social Psycholog, 635-652.

Oktaviani, A. (2016). Hubungan Antara Empati dengan Perilaku Prososial. http://eprints.ums.ac.id/48477/, 1-15.

Sabela, A., \& Komariah. (2020). Pengaruh Bimbingan Kelompok dengan Teknik Outbound untuk Meningkatkan Perilaku Prososial. IJoCE : Indonesian Journal of Counseling and Education, Vol. 1(No. 1), 24-31.

Sari, E. P. (2013). Pengembangan Model Layanan Bimbingan Kelompok dengan Teknik Sosiodrama untuk Meningkatkan Sikap Empati. journal unnes, 1-7.

Solikin, A. (2015). Bibliotherapy sebagai Sebuah Teknik dalam Layanan Bimbingan dan Konseling. Anterior Jurnal, 154-161. 